\title{
Effectiveness of Mobile Applications on Medication Adherence in Adults with Chronic Diseases: A Systematic Review and Meta-Analysis
}

\author{
Yihang Peng, MN; Han Wang, MM; Qin Fang, BS; Liling Xie, BS; \\ Lingzhi Shu, MN; Wenjing Sun, MN; and Qin Liu, PhD
}

\begin{abstract}
BACKGROUND: Medication adherence is frequently suboptimal in adults with chronic diseases, resulting in negative consequences. Traditional interventions to improve adherence are complex and not widely effective. Mobile applications may be a scalable means to support medication adherence.

OBJECTIVE: To investigate the effect of mobile apps on medication adherence in adults with chronic diseases.

METHODS: MEDLINE, EMBASE, CINAHL Plus, Cochrane Central Register of Controlled Trials, and Web of Science were searched for randomized controlled trials evaluating the effectiveness of any mobile application (app) intervention directed at patients with chronic disease to improve medication adherence in comparison with usual care. A random-effects model was used to pool the outcome data. Risk of bias and quality of study were assessed per Cochrane guidelines.
\end{abstract}

RESULTS: Fourteen studies were included in this systematic review involving 1,785 participants, 940 of whom were randomized to a mobile app intervention group and 845 to the usual care group. The meta-analysis showed that the use of mobile apps was associated with a significant improvement in patient adherence to medication (Cohen's $d=0.40,95 \%$ $\mathrm{Cl}=0.27-0.52 ; P<0.001$ ), with a low quality of GRADE evidence. There was no evidence of publication bias (Egger's test; $P=0.81$ ) or substantial heterogeneity $\left(I^{2}=29 \%\right)$. In the sensitivity analysis, our findings remained robust to change in inclusion criteria based on study quality (Cohen's $\mathrm{d}=0.43,95 \% \mathrm{Cl}=0.33-0.54 ; P<0.001)$. The included apps incorporated 9 features, sorted from high to low based on relative weights (RW): documentation $(R W=0.254)$, medication reminder $(R W=0.204)$, data sharing $(R W=0.148)$, feedback message $(R W=0.104)$, clinical decision support $(R W=0.097)$, education $(R W=0.081)$, customization $(R W=0.049)$, data statistics $(R W=0.041)$, and appointment reminder $(R W=0.041)$. In the subgroup analysis, the effect was not sensitive to study characteristics or app features $(0.37 \leq P \leq 0.95)$. App acceptability was reported by participants in the intervention group in 8 studies: 144 of 156 participants (91.7\%) were satisfied with all aspects of the apps.

CONCLUSIONS: Compared with conventional care, mobile apps are effective interventions to help improve medication adherence in adults with chronic diseases. Although promising, these results should be interpreted with caution given the low level of evidence and short intervention duration. Future research will not only need to identify ideal app features and the costs to providers but also need to improve the apps to make them user friendly, secure, and effective based on patient-centered theory.

J Manag Care Spec Pharm. 2020;26(4):550-61

Copyright $\odot 2020$, Academy of Managed Care Pharmacy. All rights reserved.

\section{What is already known about this subject}

mHealth interventions, such as short message service and electronic pillboxes, are shown to have positive effects on medication adherence.

Mobile apps have the advantage of accessibility, lower costs, and diversity suitable for chronic disease management.

\section{What this study adds}

The use of mobile apps was associated with a significant improvement of medication adherence in patients with chronic diseases. This study summarized the common and important features of the apps and provided reference for researchers to further improve and develop medication apps.

In general, patients with smart phones have a high acceptance of medication apps

$\mathrm{M}$ any chronic diseases can be treated effectively with long-term courses of medication, and adherence to medication is crucial in this process. Adherence is defined as the degree to which the patient's behavior is in agreement with his or her physician's recommendations. ${ }^{1}$ In other words, medication adherence is the process by which people take their medications as prescribed with the correct dose at the correct time. ${ }^{2}$ Among adults with chronic diseases, between $30 \%$ and $50 \%$ of medications are not taken as prescribed. ${ }^{3,4}$ Poor medication adherence can lead to health complications, worsening clinical outcomes, and increased health care costs. ${ }^{5,6}$ Treatment adherence in patients with chronic diseases is a well-established public health problem.

Various interventions have been evaluated and demonstrated to be effective in improving medication adherence, including motivational interviewing, formulary restrictions, and pharmacist-led multidisciplinary cooperation and education..$^{7-10}$ These interventions, however, are not only time consuming but also labor intensive. There is widespread need for convenient and feasible innovations to improve chronic disease management and medication adherence of patients. Mobile health (mHealth)_defined as the use of mobile and wireless 
devices to improve health outcomes, health care services, and health research—can solve this part of the problem. ${ }^{11,12}$

Some mHealth interventions, such as short message service (SMS) and electronic pillboxes, ${ }^{13,14}$ have demonstrated improved medication adherence. However, their availability within usual health care is low and presents a challenge for translation into routine clinical practice. As a type of mHealth, mobile applications (apps) are more diverse and interactive than SMS and cheaper and more convenient than electronic pillboxes. ${ }^{15}$ Mobile apps are defined as computer programs or software installed on mobile electronic devices that support a wide range of functions and uses, including television, telephone, video, music, word processing, and Internet service. ${ }^{16}$ Industry analysts reported that the number of worldwide mobile subscriptions was around 8 billion in 2019, ${ }^{17}$ which means that mobile apps cover a wide range of patients. According to the report from the IMS Institute for Healthcare Informatics, the number of mHealth apps available to consumers exceeds $165,000 .^{18}$

Although there are thousands of health apps available, there is minimal evidence for their effectiveness in improving medication adherence. A review article by Mohammadi et al. (2018) concluded that app interventions were effective for improving medication adherence on patients with cardiovascular disease. ${ }^{19}$ However, the main aim of Mohammadi et al. was to analyze the effects of apps on blood pressure management rather than medication adherence. Only 3 of the articles included in their study demonstrated the effectiveness of apps on medication adherence, and meta-analysis could not be performed. Therefore, it was necessary to conduct a systematic review and meta-analysis of the effectiveness and availability of the apps on medication adherence. The objectives of our systematic review were to (a) assess the effectiveness of mobile apps on medication adherence in adults patients with chronic disease, (b) describe and examine the effect of characteristics of app interventions, and (c) describe participant's perceptions and acceptability of apps.

\section{Methods}

This systematic review was conducted following a protocol prepared a priori and reported according to the Preferred Reporting Items for Systematic Reviews and Meta-Analyses (PRISMA) guidelines. ${ }^{20}$

\section{Search Strategy}

We conducted a systematic literature search of MEDLINE, EMBASE, CINAHL Plus, Cochrane Central Register of Controlled Trials, and Web of Science for relevant articles up to December 2018. A broad keyword strategy was employed to supplement the subject heading strategy. The keywords included (a) intervention (application*, app, apps, mobile, cellular phone*, cell phone*, mHealth, and smartphone*); (b) medication use (adheren*, nonadheren*, noncomplian*, complian*, concordan*, refusal, and refuse) were used; and (c) trial (random*, clinical, controlled, trial, double blind, single blind, and placebo). No restriction on publication date or language was applied. The references of the included studies were manually searched to identify any additional articles.

\section{Inclusion and Exclusion Criteria}

The inclusion criteria were as follows: (a) the trial studied adult patients ( $\geq 18$ years) with chronic disease (chronic diseases are defined broadly as conditions that last 1 year or more and require ongoing medical attention or limit activities of daily living or both, including cardiovascular diseases, cancers, chronic respiratory diseases, AIDS, chronic skin disease, diabetes, and organ transplantation ${ }^{21}$; (b) the study was a randomized clinical trial (RCT) with at least 4 weeks' follow-up; (c) the patients received a mobile app intervention designed to promote medication adherence; (d) the control group in the study received usual medication care; and (e) the study had to record at least 1 quantitative measure of the effect of apps on medication adherence. Exclusion criteria were as follows: (a) the mobile app was designed exclusively for use by health workers; (b) the mobile app had a singular function for text messaging; and (c) the study involved psychiatric, military, or institutionalized patients. Two reviewers searched the literature and assessed the studies independently.

\section{Data Extraction}

Two reviewers used a standardized form to extract data from the included studies for assessment of study quality and evidence synthesis. Any disagreements were resolved through discussion with a third reviewer. We extracted the study characteristics, app characteristics, app acceptability among patients, and measurements and outcomes of medication adherence from the included studies. For multiple-arm studies, we used the overall intervention effect. If not reported, we combined trial arms (i.e., app vs. non-app arms) based on the Cochrane Handbook for Systematic Reviews of Interventions. ${ }^{22}$

\section{Quality Assessment}

Risk of bias was assessed by 2 reviewers, using the quality rating tool from the Cochrane Handbook for Systematic Reviews of Interventions. ${ }^{22}$ We graded the potential bias as high, low, or unclear for each of the following domains: random sequence generation, allocation concealment, blinding of participants and personnel, blinding of outcome assessment, incomplete outcome data, selective outcome reporting, and other bias.

\section{Statistical Analysis}

Statistical analyses were performed using Review Manager version 5.3 (Nordic Cochrane Centre, Copenhagen, Denmark) and StataSE version 15 (StataCorp, College Station, TX). 


\section{FIGURE 1 PRISMA Flow Diagram}

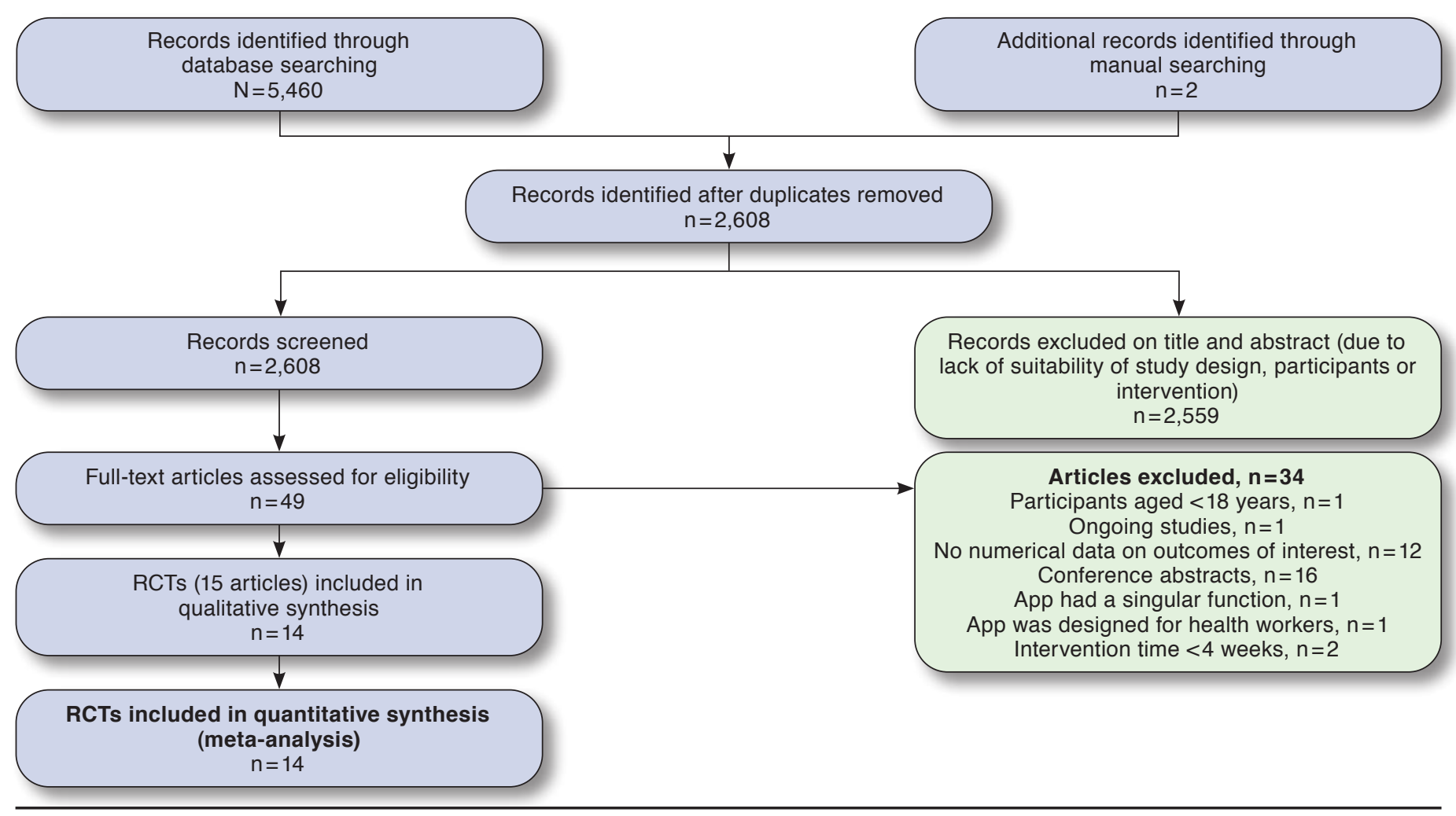

PRISMA = Preferred Reporting Items for Systematic Reviews and Meta-Analyses; RCT = randomized controlled trial.

We used the mean effect size approach to pool estimates, which has been widely accepted to guarantee the independence assumption in meta-analysis., ${ }^{5,13,23}$ Although the adherence measures varied across studies, differences in outcomes between the intervention and control groups can be measured and pooled with appropriate meta-analysis methods. ${ }^{24}$ In our study, Cohen's d was calculated as the mean effect size to determine the magnitude of the difference in medication adherence between the intervention and control groups. We calculated the standardized mean difference (SMD) for primary study and used an inverse variance random-effects model to pool estimates. A Cohen's d value of $0.2,0.5$, or 0.8 can be respectively considered as small, medium, and large effect size, respectively. ${ }^{25}$

We used statistical approaches from the Cochrane Handbook to re-express odds ratios as SMD when missing data were not collected from investigators. ${ }^{22}$ The effect size was weighted according to the study sample size. We used the $\mathrm{I}^{2}$ statistic to measure heterogeneity across the trials for the analysis of each outcome. ${ }^{22}$ The substantial heterogeneity was defined as the $\mathrm{I}^{2}$ statistic exceeding $50 \%$ with $P<0.05$. Publication bias was assessed using Egger's regression test, with $P<0.1$ considered to indicate the presence of publication bias. ${ }^{26}$
Our primary analysis included examining the effects of mobile app interventions on medication adherence. Medication adherence can be measured in a variety of ways, when multiple measures were reported for adherence in 1 study, we chose the more objective and reliable measure (e.g., electronic monitoring over pill count and self-report; continuous scale over dichotomized scale). ${ }^{27}$

The quality of evidence of primary outcomes was assessed based on the criteria of risk of bias, inconsistency, indirectness, imprecision, and reporting bias as described in the GRADE Quality Assessment Checklist. ${ }^{28}$

The relative weighting of each feature of the app was calculated by the analytic hierarchy process (AHP). ${ }^{29,30} \mathrm{~A}$ 9-point valuation scale ranging from 1 to 9 was used to compare pairwise each feature with each other feature by 2 reviewers.

\section{Subgroup Analyses}

To cope with the significant differences between studies, subgroup analyses were performed to explore factors that would moderate the overall effect size. Subgroups were defined by the participant age, country, sample size, type of disease, intervention duration, type of outcome assessing method, intervention component, and functionality of apps. 
TABLE 1 Characteristics of Included Studies and Participants

\begin{tabular}{|c|c|c|c|c|c|}
\hline Source & Disease & $\begin{array}{c}\text { Sample Size } \\
\text { (Intervention Duration) }\end{array}$ & $\begin{array}{l}\text { Mean Age } \\
\text { (Years) }\end{array}$ & $\begin{array}{c}\text { Female, } \\
\%\end{array}$ & Participant Characteristics \\
\hline $\begin{array}{l}\text { Brath et al. (2013) } 31 \\
\text { Austria }\end{array}$ & Diabetes & $\begin{array}{l}\mathrm{IG}=53, \mathrm{CG}=53 \\
(20 \text { weeks) }\end{array}$ & $69.4(4.8)$ & 45 & $\begin{array}{l}\text { Diabetes clinic outpatient with a defined risk for } \\
\text { cardiovascular conditions }\end{array}$ \\
\hline $\begin{array}{l}\text { Contreras et al. (2018) })^{32} \\
\text { Spain }\end{array}$ & HTN & $\begin{array}{l}\mathrm{IG}=73, \mathrm{CG}=75 \\
(12 \text { months })\end{array}$ & $\begin{array}{l}\mathrm{IG}=57.7(9) \\
\mathrm{CG}=57.1(10)\end{array}$ & 52 & $\begin{array}{l}\text { Outpatient receiving an antihypertensive tablet for } \\
\text { at least } 1 \text { month }\end{array}$ \\
\hline $\begin{array}{l}\text { Dabbs et al. (2016) } \\
\text { United States }\end{array}$ & $\begin{array}{l}\text { Lung transplant } \\
\text { recipients }\end{array}$ & $\begin{array}{l}\mathrm{IG}=99, \mathrm{CG}=102 \\
(12 \text { months) }\end{array}$ & $\begin{array}{l}\mathrm{IG}=61.7(3.2) \\
\mathrm{CG}=61.7(3.4)\end{array}$ & 44.8 & Recruited during their transplant hospitalization \\
\hline $\begin{array}{l}\text { Guo et al. }(2017)^{35} \\
\text { China }\end{array}$ & Atrial fibrillation & $\begin{array}{l}\text { IG }=113, C G=96 \\
\text { (3 months) }\end{array}$ & $\begin{array}{l}\mathrm{IG}=67.4(10.6) \\
\mathrm{CG}=70.9(17.4)\end{array}$ & 56 & $\begin{array}{l}\text { Hospital inpatient with atrial fibrillation diag- } \\
\text { nosed }\end{array}$ \\
\hline $\begin{array}{l}\text { Himelhoch et al. (2017) } \\
\text { United States }\end{array}$ & AIDS & $\begin{array}{l}\mathrm{IG}=19, \mathrm{CG}=9 \\
\text { (3 months) }\end{array}$ & $\begin{array}{l}\mathrm{IG}=44.6(10.7) \\
\mathrm{CG}=53.1(4.4)\end{array}$ & 32 & $\begin{array}{l}\text { HIV clinic outpatient with having a self-reported } \\
\text { lifetime history of drug or alcohol use }\end{array}$ \\
\hline $\begin{array}{l}\text { Kim et al. }(2016)^{37} \\
\text { United States }\end{array}$ & HTN & $\begin{array}{l}\text { IG }=52, C G=43 \\
\text { (6 months) }\end{array}$ & $\begin{array}{l}\mathrm{IG}=57.5(8.6) \\
\mathrm{CG}=57.7(8.7)\end{array}$ & 68 & $\begin{array}{l}\text { Hospital patient had a diagnosis of hypertension } \\
\text { and been able to access the Internet }\end{array}$ \\
\hline $\begin{array}{l}\text { Kleinman et al. (2017) }{ }^{38} \\
\text { India }\end{array}$ & Type 2 diabetes & $\begin{array}{l}\mathrm{IG}=44, \mathrm{CG}=46 \\
\text { (6 months) }\end{array}$ & $\begin{array}{l}\mathrm{IG}=48.8(9.0) \\
\mathrm{CG}=48.0(9.5)\end{array}$ & 30 & $\begin{array}{l}\text { Diabetes-focused clinics patient on stable diabetes } \\
\text { therapy for }>3 \text { months with type } 2 \text { diabetes }\end{array}$ \\
\hline $\begin{array}{l}\text { Labovitz et al. (2017) } \\
\text { United States }\end{array}$ & Stroke & $\begin{array}{l}\mathrm{IG}=15, \mathrm{CG}=13 \\
(12 \text { weeks) }\end{array}$ & $\begin{array}{l}I G=58.3(9.8) \\
C G=55.5(16.6)\end{array}$ & 54 & Outpatient receiving oral anticoagulation therapy \\
\hline $\begin{array}{l}\text { Mira et al. (2014) } \\
\text { Spain }\end{array}$ & Chronic disease & $\begin{array}{l}\mathrm{IG}=5 \mathrm{l}, \mathrm{CG}=48 \\
\text { ( } 3 \text { months) }\end{array}$ & $\begin{array}{l}C G=72.9(6) \\
I G=70.9(8)\end{array}$ & 44 & Hospital outpatient taking multiple medications \\
\hline $\begin{array}{l}\text { Morawski et al. (2018) } 40 \\
\text { United States }\end{array}$ & HTN & $\begin{array}{l}I G=209, C G=202 \\
(12 \text { weeks) }\end{array}$ & $\begin{array}{l}\mathrm{IG}=51.7(10.5) \\
\mathrm{CG}=52.4(10.1)\end{array}$ & 60.1 & Receiving treatment for at least 1 month \\
\hline $\begin{array}{l}\text { Santo et al. (2018) } \\
\text { Australia }\end{array}$ & CVD & $\begin{array}{l}\text { IG }=101, C G=51 \\
\text { (3 months) }\end{array}$ & $\begin{array}{l}\mathrm{IG}=58.4(9.04) \\
\mathrm{CG}=56.8(8.64)\end{array}$ & 12.3 & Hospital patient had a diagnosis of $\mathrm{CHD}$ \\
\hline $\begin{array}{l}\text { Sarfo et al. (2018) } \\
\text { Ghana }\end{array}$ & Stroke & $\begin{array}{l}\mathrm{IG}=30, \mathrm{CG}=30 \\
(3 \text { months) }\end{array}$ & $\begin{array}{l}\mathrm{IG}=54.3(11.9) \\
\mathrm{CG}=55.9(13.7)\end{array}$ & 35 & $\begin{array}{l}\text { Outpatient with a recent confirmed stroke of }<1 \\
\text { month and uncontrolled hypertension }\end{array}$ \\
\hline $\begin{array}{l}\text { Shah et al. (2016) } \\
\text { United States }\end{array}$ & PCI & $\begin{array}{l}\mathrm{IG}=13, \mathrm{CG}=11 \\
(3 \text { months })\end{array}$ & $\begin{array}{l}\mathrm{IG}=60.5(8.9) \\
\mathrm{CG}=60.6(4.1)\end{array}$ & 42 & $\begin{array}{l}\text { Had a percutaneous coronary intervention with a } \\
\text { DES at hospital }\end{array}$ \\
\hline $\begin{array}{l}\text { Svendsen et al. (2018) } \\
\text { Denmark }\end{array}$ & Psoriasis & $\begin{array}{l}\mathrm{IG}=68, C G=66 \\
(4 \text { weeks) }\end{array}$ & $48(10.4)$ & 38.8 & $\begin{array}{l}\text { Hospital outpatient who were diagnosed with } \\
\text { mild-to-moderate psoriasis }\end{array}$ \\
\hline
\end{tabular}

$C A D=$ coronary artery disease $C V D=$ cardiovascular disease; $C G=$ control group; $D E S=$ drug-eluting stent; HIV=human immunodeficiency virus; HTN = hypertension; $I G=$ intervention group; $P C I=$ percutaneous coronary intervention.

\section{Results}

\section{Identified and Included Studies}

The PRISMA flowchart (Figure 1) shows the identified papers, screening process, and final number of studies included. In summary, we identified 5,462 articles from searching; 2,608 were screened after removing duplicate records, and 2,559 were excluded. A total of 49 full-text articles were assessed for eligibility, and 15 were finally included. ${ }^{31-44}$

\section{Characteristics of Included Studies}

There were 1,785 participants in the 14 studies (Table 1). The median sample size was 128 (range, 24-411), and the mean age of participants ranged from 45 to 73 years (median 57 years). The following chronic diseases were included in the studies: cardiovascular disease, $32,35,37,40,41,43$ stroke, ${ }^{34,42}$ AIDS, ${ }^{36}$ diabetes mellitus, ${ }^{31,38}$ lung transplant, ${ }^{33}$ and psoriasis. ${ }^{44}$ The median intervention duration was 3 months (range 1-12).

The characteristics of the RCTs are presented in Table 2 . There were 3 trials represented medication adherence by the proportion of adherent patients, ${ }^{33,38,44} 5$ trials by average adherence score, ${ }^{35,37,39-41}$ and 6 trials by the proportion of medication taken as prescribed. ${ }^{31,32,34,36,42,43}$ The most commonly used method to assess adherence was self-report, ${ }^{33,35,37,38-41}$ followed by pill count ${ }^{31,36,42,43}$ and medication event monitoring system. ${ }^{31,32,44}$ One trial did not explain the outcome assessing method. In all interventions, there were researchers who trained participants how to use the app. ${ }^{34}$ In 7 interventions, there were study physicians who provided consultation based on the participants' own data monitored by app. ${ }^{31,33,35-38,42}$ The intervention arms in 8 studies were composed of app only. $32,33,35,38-41,43$ Beyond that, 4 studies included a linked clinician interface, ${ }^{31,34,36,37}$ and 4 studies included Bluetooth and electronic monitor in the intervention arms. ${ }^{31,37,42,44}$

\section{Apps Featured in the Included Studies}

In all studies, 8 apps were designed for just 1 particular disease, , $^{32,33,35-38,43,44}$ and 5 were for all patients with chronic diseases who need medication. ${ }^{31,34,39-41}$ Ten apps were designed and set up by study's researchers, ${ }^{31,33-39,43,44}$ and 3 were freely available in app stores. ${ }^{32,40,41}$ Theoretical frameworks for designing apps were only mentioned in 3 studies. ${ }^{33,38,43}$ One study was guided by Orem's theory of self-care and adopted a 
TABLE 2 Characteristics of the Randomized Clinical Trials

\begin{tabular}{|c|c|c|c|c|c|}
\hline Source & Trial & Intervention Components & App Functions & $\begin{array}{c}\text { Outcome Measure/Outcome } \\
\text { Ascertainment Method }\end{array}$ & $\begin{array}{l}\text { Mean Outcomes } \\
\text { (SD) }\end{array}$ \\
\hline Brath et al. ${ }^{31}$ & App vs. UC & $\begin{array}{l}\text { Internet, app, embedded } \\
\text { microelectronic, researchers, } \\
\text { counselors }\end{array}$ & $\begin{array}{l}\text { Documentation, MR, DS, } \\
\text { FM }\end{array}$ & PDT/pill counts, MEMS & $\begin{array}{l}\mathrm{IG}=99.56(1.22) \\
\mathrm{CG}=99.43(1.76)\end{array}$ \\
\hline Contreras et al. ${ }^{32}$ & App vs. UC & App (AlerHTA), researchers & $\begin{array}{l}\text { Documentation, education, } \\
\text { MR, AR, DS, customization }\end{array}$ & $\begin{array}{l}\text { PDT (> }>80 \% \text { of medications } \\
\text { taken)/MEMS }\end{array}$ & $\begin{array}{l}\mathrm{IG}=86.3(34.3) \\
\mathrm{CG}=62.7(48.3)\end{array}$ \\
\hline Dabbs et al. ${ }^{33}$ & App vs. UC & $\begin{array}{l}\text { App (Pocket PATH), researchers, } \\
\text { transplant coordinator }\end{array}$ & $\begin{array}{l}\text { Documentation, DS, FM, } \\
\text { CDS }\end{array}$ & PPA ( $\geq 8$ points)/self-report & $\mathrm{OR}=2.27(1.01-2.66)$ \\
\hline Guo Y et al. ${ }^{35}$ & App vs. UC & App (mAF), researchers, counselors & $\begin{array}{l}\text { Documentation, education, } \\
\text { AR, DS, FM, CDS }\end{array}$ & $\begin{array}{l}\text { PPA/self-report } \\
\text { (3-item Adherence Estimator) }\end{array}$ & $\begin{array}{l}\mathrm{IG}=2.0(3.03) \\
\mathrm{CG}=5.1(8.28)\end{array}$ \\
\hline Himelhoch et al. ${ }^{36}$ & App vs. UC & $\begin{array}{l}\text { App (Heart2HAART), researchers, } \\
\text { linked clinician interface, counselors }\end{array}$ & $\begin{array}{l}\text { Documentation, education, } \\
\text { MR, DS, FM, data statistics }\end{array}$ & PDT/pill counts & $\begin{array}{l}\mathrm{IG}=92.69(19.63) \\
\mathrm{CG}=99.48(15.54)\end{array}$ \\
\hline Kim et al. ${ }^{37}$ & App vs. UC & $\begin{array}{l}\text { APP, BP monitor, Internet-based } \\
\text { dashboards, researchers, counselors }\end{array}$ & Documentation, DS, FM & $\begin{array}{l}\text { PPA/self-report } \\
\text { (MMAS-8 item) }\end{array}$ & $\begin{array}{l}\mathrm{IG}=6.7(1.4) \\
\mathrm{CG}=6.5(1.5)\end{array}$ \\
\hline Kleinman et al. ${ }^{38}$ & App vs. UC & $\begin{array}{l}\text { APP, web portal, researchers, } \\
\text { counselors }\end{array}$ & $\begin{array}{l}\text { Documentation, MR, DS, } \\
\text { FM, CDS }\end{array}$ & $\begin{array}{l}\text { PPA (all medications taken)/ } \\
\text { self-recall ( } 7 \text { days) }\end{array}$ & $\mathrm{OR}=2.56(1.99-3.13)$ \\
\hline Labovitz et al. ${ }^{34}$ & App vs. UC & $\begin{array}{l}\text { App, Internet-based dashboards, } \\
\text { researchers }\end{array}$ & $\begin{array}{l}\text { Documentation, education, } \\
\text { MR, DS }\end{array}$ & $\begin{array}{l}\text { PDT/unspecified, } \\
\text { plasma sampling }\end{array}$ & $\begin{array}{l}I G=97.2(4.4) \\
C G=90.6(5.8)\end{array}$ \\
\hline Morawski et al. ${ }^{40}$ & App vs. UC & APP (Medisafe), researchers & $\begin{array}{l}\text { Documentation, MR, DS, } \\
\text { FM }\end{array}$ & $\begin{array}{l}\text { PPA/self-report } \\
\text { (MMAS-8 item) }\end{array}$ & $\begin{array}{l}\mathrm{IG}=6.3(1.6) \\
\mathrm{CG}=5.7(1.8)\end{array}$ \\
\hline Santo et al. ${ }^{41}$ & $\begin{array}{l}\text { Basic App vs. } \\
\text { Advanced } \\
\text { App vs. UC }\end{array}$ & APP, researchers & $\begin{array}{l}\text { Documentation, MR, DS, } \\
\text { data statistics }\end{array}$ & $\begin{array}{l}\text { PPA/self-report } \\
\text { (doses missed over } 7 \text { days, } \\
\text { MMAS-8 item) }\end{array}$ & $\begin{array}{l}\mathrm{IG}=7.11(1.1) \\
\mathrm{CG}=6.63(1.0)\end{array}$ \\
\hline Sarfo et al. ${ }^{42}$ & App vs. UC & $\begin{array}{l}\text { App, Bluetooth sync, BP monitor, } \\
\text { researchers, counselors }\end{array}$ & $\begin{array}{l}\text { Documentation, MR, DS, } \\
\text { FM }\end{array}$ & $\begin{array}{l}\text { PDT/pill count (medication } \\
\text { possession ratio) }\end{array}$ & $\begin{array}{l}\mathrm{IG}=0.88(0.40) \\
\mathrm{CG}=0.64(0.45)\end{array}$ \\
\hline Shah et al. ${ }^{43}$ & App vs. UC & App (My IDEA), researchers & $\begin{array}{l}\text { Documentation, education, } \\
\text { DS, customization }\end{array}$ & $\begin{array}{l}\text { PPA ( }>80 \% \text { of medications } \\
\text { taken)/pill count ( } 90 \text { days, } \\
\text { medication possession } \\
\text { ratio), blood tests }\end{array}$ & $\begin{array}{l}\mathrm{IG}=0.95(0.22) \\
\mathrm{CG}=0.85(0.24)\end{array}$ \\
\hline Svendsen et al. ${ }^{44}$ & App vs. UC & $\begin{array}{l}\text { App, Bluetooth sync, electronic } \\
\text { monitor, researchers }\end{array}$ & Documentation, education & $\begin{array}{l}\text { PPA }(>80 \% \text { of medications } \\
\text { taken)/MEMS }\end{array}$ & $\mathrm{OR}=3.22(1.42-6.28)$ \\
\hline
\end{tabular}

Note: Researchers trained participants on how to use the application; counselors provided counseling services when needed.

$A R=$ appointment reminder; $B P=$ blood pressure; $C D S=$ clinical decision support $; C G=$ control group; $D S=$ data sharing; $F M=$ feedback message; $I G=$ intervention group; MEMS = medication event monitoring system; MMAS = modified Morisky Adherence Scale; MR=medication reminder; OR=odds ratio; PDT = proportion of doses taken; $P P A=$ proportion of patients adherent; $S D=$ standard deviation; $U C=$ usual care.

user-centered design approach by involving patients in the design and testing of apps. ${ }^{33}$ A study based on the theory of behavior change established an evidence-based app platform, including the health belief model, health action process approach, theory of planned behavior, and Bandura's theory of self-efficacy. ${ }^{38}$ Another study used Kolb's experiential learning theory to build an app's health education module. ${ }^{43}$ There were 9 app features in the 14 interventions (Table 2): documentation, education, medication reminder, appointment reminder, data sharing, feedback message, customization, clinical decision support, and data statistics. Every app contained more than 2 features. Five apps included 5 or more features. ${ }^{32,35,36,38,39}$ Apps in all included studies could document the status of personal medication use record, and 2 of them evaluated medication adherence periodically. ${ }^{36,41}$ Most apps had a medication reminder feature. . $^{31,32,34,36,38-42,44}$ Nine apps reminded participants to take their medication at a fixed, predetermined frequency. ${ }^{32,34,36,38-42,44}$ Four apps used real-time medication monitoring in which participants were reminded if they failed to take medicine..$^{31,34,40,41}$ Four apps provided clinical decision support for how to use medication correctly. $33,35,38,39$ Seven apps provided education about illness and medication for patients, ${ }^{32,34-36,39,43,44}$ and 2 of them were individualized. ${ }^{39,43}$ All but 2 apps shared patients health data with physicians in strictest confidence, ${ }^{43,44}$ and 2 of them shared data with family or friends, sharing controlled by patients. ${ }^{40,41}$ Seven apps received feedback messages from physicians based on data. ${ }^{31,33,35-38,42}$ Two apps would remind patients of upcoming appointments with physicians..$^{32,35}$ Only 1 app provided a calendar and allowed patients to set personal goals. ${ }^{32}$ The most common combination of feature was documentation, medication reminder, and data sharing. Importance weights of the features of the apps obtained through AHP were as follows: documentation (relative weight $[\mathrm{RW}]=0.254$ ), medication reminder $(R W=0.204)$, data sharing $(R W=0.148)$, feedback message $(R W=0.104)$, clinical decision support $(R W=0.097)$, 


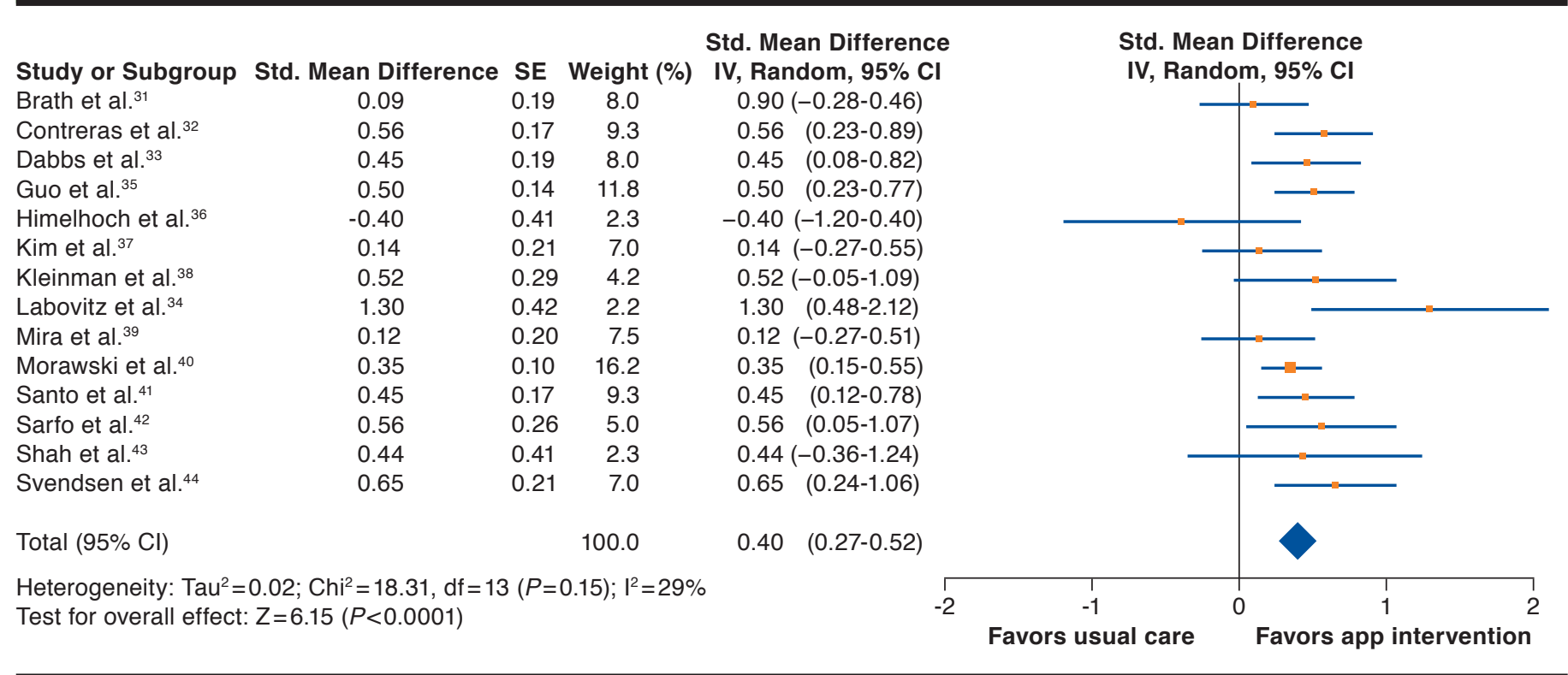

$C I=$ confidence interval; $d f=$ degrees of freedom; $I^{2}=$ Higgins $I^{2}$ statistic; $I V=$ inverse variance method; $S E=$ standard error; Std =standardized; $Z=$ test statistic resulting from the statistical test used to derive the $P$ value.

education ( $R W=0.081)$, customization $(R W=0.049)$, data statistics $(\mathrm{RW}=0.041)$ and appointment reminder $(\mathrm{RW}=0.041)$. The overall ranking consistency is satisfactory (credible inter$\mathrm{val}=0.041$; credible region $=0.027$ )

\section{Meta-Analysis of the Intervention Efficacy}

The pooled estimate based on data from 1,785 patients showed that the mobile application interventions improved medication adherence significantly (Cohen's $d=0.40,95 \% \mathrm{CI}=0.27-0.52$; $P<0.001$ ), see Figure 2. We did not find significant effects of applications on adherence in the subgroup analysis based on characteristics of the included studies and mobile applications (Table 3). There was low heterogeneity $\left(\mathrm{I}^{2}=29 \%, 95 \%\right.$ $\mathrm{CI}=0 \%-62 \% ; P=0.15)$ across the trials. Publication bias was not found by Egger regression coefficient $(P=0.81)$.

\section{Risk of Bias and Quality Assessment}

Nine studies reported adequate random sequence generation and were at low risk of bias for this domain. ${ }^{32,33,35,38-42,44}$ Three studies adequately described their allocation concealment. ${ }^{33,38,42}$ Only 1 study masked the participants and personnel during the study. ${ }^{40}$ Ten studies blindly assessed the primary outcome variables. ${ }^{31-33,35,38-42,44}$ In most studies, risk of bias was low in relation to incomplete outcome data. ${ }^{32-34,36,38-43}$ Eight studies reported outcomes as planned in their protocol. . $^{32,33,35,38-41,44}$ We rated 1 study as having other bias because groups were not balanced at baseline for controlling hypertension in this study. ${ }^{37}$ Overall, 5 studies were thought to have high-risk of bias (Appendix A, available in online article). ${ }^{31,34,36,37,43}$

Across all studies considered in this review, the GRADE evidence table determined an overall low quality of evidence for the intervention on medication adherence (Appendix B, available in online article). The overall body of evidence was downgraded due to serious risk of bias (absence of blinding across studies) and indirectness (different chronic conditions, different outcome measures, and different features of apps in different studies).

\section{Sensitivity Analysis}

The sensitivity analysis was performed based on the quality of studies. The effect of apps on patient adherence to medication increased slightly when we excluded studies with high risk of bias (Cohen's d $=0.43,95 \% \mathrm{CI}=0.33-0.54 ; P<0.001$ ). When we excluded 4 studies with incomplete outcome data, ${ }^{31,35,37,44}$ the effect of application on medication adherence did not change (Cohen's $\mathrm{d}=0.39,95 \% \mathrm{CI}=0.22-0.55 ; \mathrm{P}<0.001$ ).

\section{Mobile Application Acceptability}

In 8 studies ( $n=772$ ), app acceptability was reported by participants of the intervention group, reflecting their satisfaction with the way the app functioned..$^{31-34,36,37,39,40}$ In all, (a) 144 of 156 participants (91.7\%) were satisfied with all aspects of the app, ${ }^{31,34,38,39}$ (b) 295 of 330 participants (89.4\%) agreed that the apps were easy and user friendly, $31,35,36,39,41$ (c) 235 of 


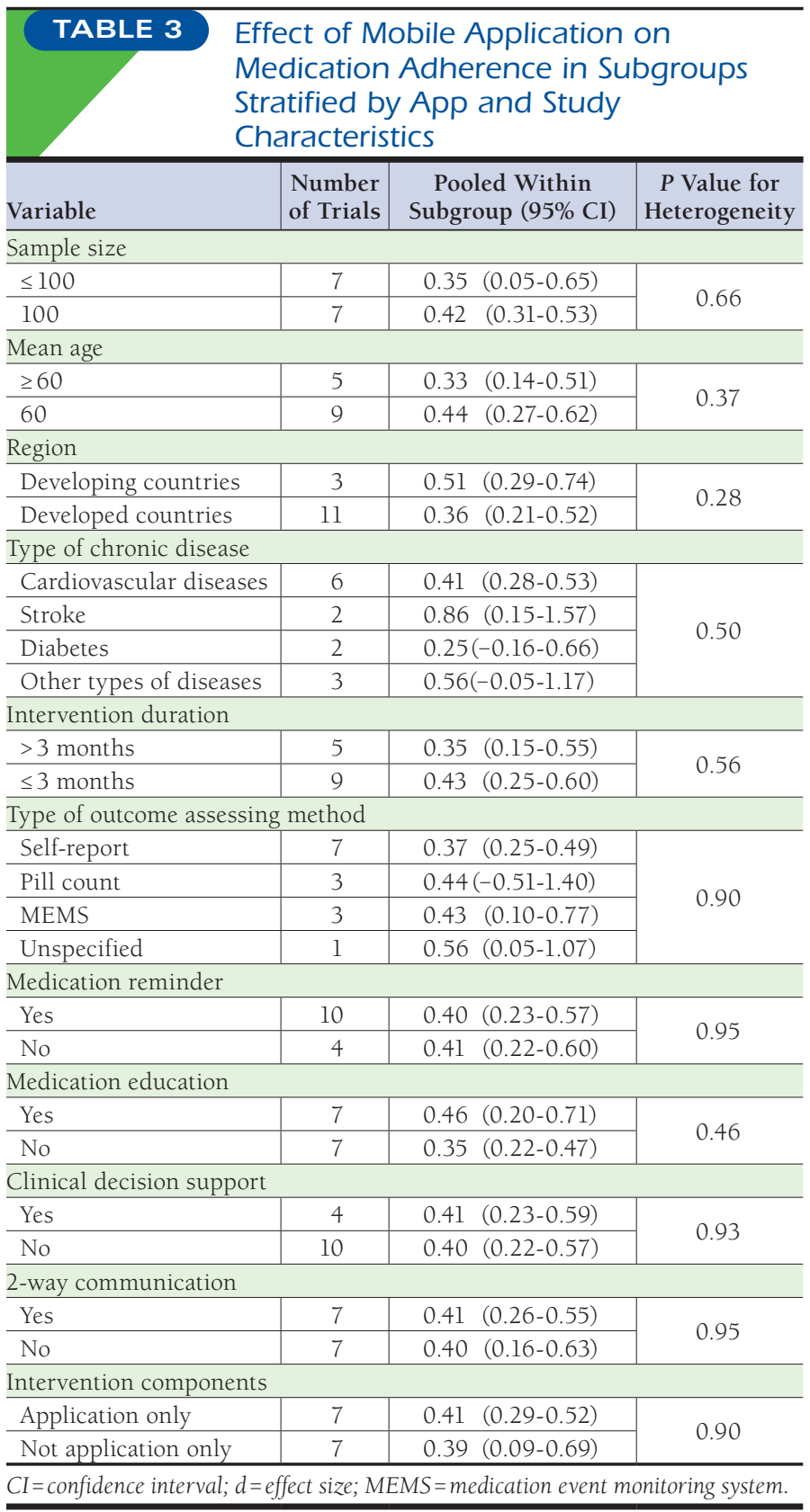

278 participants (84.5\%) felt that apps improved their independence in managing their medications, ${ }^{35,36,39,41}$ (d) 191 of 220 participants $(86.8 \%)$ believed it could improve effective communication between doctors and patients, ${ }^{31,35,36,38}$ and (e) 75 of 98 participants (76.5\%) said they would continue to use and share with friends. ${ }^{41}$ One study observed that intermittent Internet connectivity issues would affect usage of apps. ${ }^{42}$ Another study found about a 25\% reduction in the use of apps over the 3-month trial because apps lacked continuous innovation of functions, such as updating contents of health education or giving participants awarded points for completing tasks to encourage their participation. ${ }^{36}$ Only 2 studies reported the acceptability of physicians for apps. ${ }^{36,38}$ In 1 study, all providers found the app helpful to their practice and the time they spent on it acceptable, ${ }^{38}$ but in another study, 2 of 4 physicians reported it was burdensome to respond to alerts sent by participants. $^{36}$

\section{Discussion}

To our knowledge, this is the first systematic review and metaanalysis of the efficacy of mobile apps for medication adherence in patients with chronic disease. The efficacy of apps found in this meta-analysis is close to that of the meta-analysis of Thakkar et al. (2016), which found that SMS interventions increased medication adherence, with a nearly doubling of the odds of patients achieving medication adherence (Cohen's $\mathrm{d}=0.41, \mathrm{OR}=2.11) .{ }^{13}$ In other words, if the medication adherence rate of patients with chronic disease is assumed to be $50 \%$, SMS interventions can increase the rate to $67.8 \%$, while app interventions remain consistent. Although the quality of some articles included in this study was not high, the effect estimate was still significantly positive even when we included only high-quality studies. In addition, our analyses found no evidence of publication bias or substantial heterogeneity; therefore, our results are credible.

The effect size of apps in this study is higher than previously reported in meta-analyses of motivational interviewing $(\mathrm{SMD}=0.23),{ }^{7}$ educational $(\mathrm{SMD}=0.33),{ }^{27}$ and psychological interventions ( $\mathrm{SMD}=0.34) .{ }^{45}$ It might suggest that mobile apps are more effective on medication adherence of patients with chronic diseases than traditional (non-mHealth) interventions. The effect of apps in this study is also higher than previously reported for electronic reminders, which included SMS, alarm devices, pagers, and beepers (Cohen's $d=0.29) .{ }^{23}$ Therefore, we think that apps may improve the medication adherence of patients more effectively than other electronic reminders.

One review showed that most health apps do not have a unified theoretical basis, which is similar to the result of this study. ${ }^{46}$ Without health behavior theory guiding app design, apps may be perceived by patients as not being helpful in promoting medication adherence. The self-determination theory of motivation posits that inner motivation (personal endorsement of health behaviors) promotes long-term behavioral change, but it requires support for 3 behavior needs: (a) competence of medication self-management, (b) personalized choice, and (c) relatedness or connectivity. ${ }^{47}$ Therefore, apps need to provide incentive support for patients based on theory to effectively help patients manage their medication, such as providing personalized education for patients or promoting health care providers by sharing health data and reports.

Another area of interest is the effect of mobile app characteristics. Maybe it's because almost all apps included in our study are advanced, the effect did not change with different functions 
of apps in the subgroup analysis. Briefly, advanced medication reminder apps are those that have interactive and custom features in addition to a single function for text messaging, education, and data upload. ${ }^{48}$ For advanced apps, in addition to medication reminders, the main function that can theoretically improve medication adherence is still unclear. In 1 of the studies we included, there was no significant difference in patients using the basic app versus the advanced app. ${ }^{41}$ However, because it was a small study with short-term follow-up and had limited power to detect meaningful differences in clinical outcomes measures, future research is still needed to verify which features of apps make them more effective. In addition to the effect of medication adherence, complex features may attract more users to download apps, help add to their interest, and contribute to the longevity of their engagement.

In addition, chronic disorders are more common among elderly people, who may not have good digital literacy, and it may be more difficult for them to use apps. ${ }^{49,50}$ Most current apps are conceived for patients familiar with these technologies, ${ }^{51}$ and elderly patients have not been consulted about the design, although it's important to involve patients in the design of apps. ${ }^{52}$ We need to be patient-centric and explore additional apps with a novel friendliness user interface that can be applied to most patients. What's more, most apps have been designed for just 1 particular disease, which could be a challenge to long-term use. We also encourage developers and researchers to develop apps and devices suited to patients with multimorbidity. Another area of concern is the privacy and security of patients data. More than 50\% of smartphone users refused to use an app because they feared their personal information would be compromised. ${ }^{53}$ So all medication apps need a Health Insurance Portability and Accountability Act compliant server to keep the patient's medication information private.

In general, the acceptance rate of the participants for mobile apps is relatively high. Most of them were satisfied with the functionality, usability, usefulness, and simplicity of the apps. However, the patients who agreed to participate in the application-based intervention studies generally have good digital literacy. One study found that 37\%-39\% of patients with chronic disease did not own a smartphone or owned phones without IOS or Android operating systems. ${ }^{54}$ But with the growth of smartphone users around the world, barriers to technology and ownership are likely to be rapidly overcome. In the near future, the number of patients who download and apply medication apps will likely increase. All participants obtained the apps free of charge from the app stores or researchers. A systematic review showed that $79.5 \%(147 / 185)$ of the apps that improve medication adherence found in Google Play were free to download, and the rest required a payment at a median cost of AUD 1.88 (\$1.23 in U.S. dollars). ${ }^{48}$ This shows that mobile phone apps are accessible due to low costs for users who want to improve medication adherence through the mobile apps.
Although our study shows that mobile apps are beneficial in improving patient medication adherence, there are still many problems waiting to be further improved. The overall strength of evidence was low as evaluated using the GRADE approach, meaning that further research is very likely to change these estimates of effect. The overall quality of the articles included was also not high. In addition to the lack of rigorous research design, the poor reporting was also an important reason for this result. In the future, researchers should design and conduct studies rigorously based on the quality rating tool for RCTs, especially paying attention to random allocation and the triple blind. In addition, the included RCTs had short intervention duration and follow-up (median, 3 months), suggesting the uncertainty of effect duration. Thus long-term (> l year) studies are also needed to estimate the effect of apps on patients who are treated for more than 1 year. What's more, only 2 included studies have provided a cursory report on physicians' satisfaction with the mobile apps, so the usability of apps for health care professionals is still unclear. When using apps in the context of clinical care, a large amount of interaction can take up too much time for the physicians, and too many alerts can exhaust them. It may be a barrier to widespread clinical care use. In addition to the time cost, the costs of developing and managing apps is also unclear. None of the included studies conducted a cost-effectiveness analysis of the development and use of apps. Future studies must take into account the significant clinical relevance of apps. How much time and money does the providers spend on it? And what frequency of alert and interaction can promote patients adherence and reduce staff workload?

\section{Limitations}

There are several possible limitations in this study. First, although we did not find publication bias by meta-analysis, publication bias cannot be ruled out because this review was restricted to published studies. ${ }^{55}$

Second, pooling different adherence measures might be a methodologic defect, although Cohen's d was used to standardize these measures and an agreed meta-analysis method was used to size the pooling effect by us. Third, many studies determined the outcomes by self-reporting, which may cause social desirability bias or recall bias. ${ }^{56}$

Finally, several moderators factors examined in the subgroup analyses may be cross-confounding, although we found no significant heterogeneity of effects across subgroups. Also, the small number of included trials limited the subgroup analyses, meaning that the findings cannot be considered conclusive.

\section{Conclusions}

In the current technology-driven world, apps are taking up more and more space in our daily lives. This review suggests 
that easy accessibility, diversity, and lower costs for users make mobile apps appear to be a potentially effective method of improving medication adherence of patients with chronic diseases. There is still some room for improvement. Future research will need to not only identify ideal app features and costs to providers but also to improve the apps to make them user friendly and secure and to help them remain effective based on patient-centered theory.

\section{Authors}

YIHANG PENG, MN; LILING XIE, BS; LINGZHI SHU, MN; and WENJING SUN, MN, First Affiliated Hospital of Chongqing Medical University, Chongqing, China. HAN WANG, MM, Department of Joint Surgery; QIN FANG, BS, Department of Cardiovasology; and QIN LIU, PhD, School of Public Health \& Management, Chongqing Medical University, Chongqing, China.

AUTHOR CORRESPONDENCE: Qin Fang, BS, Department of Cardiovasology, First Affiliated Hospital of Chongqing Medical University, Chongqing, China. Tel. : 00 +86139833 68258; E-mail: 949560838@qq.com.

\section{DISCLOSURES}

Funding for this study was provided by Chongqing Science and Technology Bureau (No. cstc2017shmsA130115). The funders had no role in study design, data collection and analysis, decision to publish, or preparation of the manuscript. The authors have no conflicts of interest to disclose.

\section{REFERENCES}

1. Sabate E; World Health Organization. Adherence to long-term therapies: evidence for action. 2003. Available at: http://apps.who.int/iris/bitstream/10665/42682/1/9241545992.pdf. Accessed February 24, 2020.

2. Vrijens B, De Geest S, Hughes DA, et al. A new taxonomy for describing and defining adherence to medications. Br J Clin Pharmacol. 2012;73(5):691-705.

3. Naderi SH, Bestwick JP, Wald DS. Adherence to drugs that prevent cardiovascular disease: meta-analysis on 376,162 patients. Am J Med. 2012;125(9):882-87.

4. Briesacher BA, Andrade SE, Fouayzi H, Chan KA. Comparison of drug adherence rates among patients with seven different medical conditions. Pharmacotherapy. 2008;28(4):437-43.

5. DiMatteo MR, Giordani PJ, Lepper HS, Croghan TW. Patient adherence and medical treatment outcomes: a meta-analysis. Med Care. 2002;40(9):794-811.

6. Schiff GD, Fung S, Speroff T, McNutt RA. Decompensated heart failure: symptoms, patterns of onset, and contributing factors. Am J Med. 2003;114(8):625-30.

7. Zomahoun HTV, Guenette L, Gregoire JP, et al. Effectiveness of motivational interviewing interventions on medication adherence in adults with chronic diseases: a systematic review and meta-analysis. Int J Epidemiol. 2017:46(2):589-602

8. Davis EM, Packard KA, Jackevicius CA. The pharmacist role in predicting and improving medication adherence in heart failure patients. J Manag Care Spec Pharm. 2014;20(7):741-55. Available at: https://www.jmcp.org/ doi/10.18553/jmcp.2014.20.7.741.
9. Happe LE, Clark D, Holliday E, Young T. A systematic literature review assessing the directional impact of managed care formulary restrictions on medication adherence, clinical outcomes, economic outcomes, and health care resource utilization. J Manag Care Spec Pharm. 2014;20(7):677-84. Available at: https://www.jmcp.org/doi/10.18553/jmcp.2014.20.7.677.

10. Zhang NJ, Terry A, McHorney CA. Impact of health literacy on medication adherence: a systematic review and meta-analysis. Ann Pharmacother. 2014;48(6):741-51.

11. World Health Organization. mHealth: new horizons for health through mobile technologies: based on the findings of the Second Global Survey on eHealth. 2011. Available at: https://apps.who.int/iris/bitstream/handle/10665/44607/9789241564250_eng.pdf;jsessionid=2D3A90D4A8D96FE0 B08F07BF0639A06F?sequence=1. Accessed February 24, 2020.

12. Ryu S. Book review: mHealth: new horizons for health through mobile technologies: based on the findings of the Second Global Survey on eHealth (Global Observatory for eHealth Series, Volume 3). Healthc Inform Res. 2012;18(3):231-33. Available at: https://www.ncbi.nlm.nih.gov/pmc/articles/ PMC3483482/. Accessed March 9, 2020.

13. Thakkar J, Kurup R, Laba TL, et al. Mobile telephone text messaging for medication adherence in chronic disease: a meta-analysis. JAMA Intern Med. 2016;176(3):340-49.

14. Choudhry NK, Krumme AA, Ercole PM, et al. Effect of reminder devices on medication adherence: the REMIND randomized clinical trial. JAMA Intern Med. 2017;177(5):624-31

15. Hou C, Ben C, Jonathan H, Trevor F, Sharon M. Do mobile phone applications improve glycemic control (HbAlc) in the self-management of diabetes? A systematic review, meta-analysis, and GRADE of 14 randomized trials. Diabetes Care. 2016;39(11):2089-95.

16. National Center for Biotechnology Information. MeSH database: mobile applications. 2014. Available at: https://www.ncbi.nlm.nih.gov/ mesh/?term=mobile+application. Accessed February 24, 2020.

17. Ericsson. Ericsson mobility report. November 2019. Available at: https:// www.ericsson.com/4acd7e/assets/local/mobility-report/documents/2019/ emr-november-2019.pdf. Accessed February 24, 2020.

18. Aitken M, Lyle J; IMS Institute for Healthcare Informatics. Patient adoption of mHealth: use, evidence and remaining barriers to mainstream acceptance. September 2015. Available at: https://www.iqvia.com/-/media/iqvia/ pdfs/institute-reports/patient-adoption-of-mhealth.pdf. Accessed February 24, 2020.

19. Mohammadi R, Ayatolahi Tafti M, Hoveidamanesh S, Ghanavati R, Pournik O. Reflection on mobile applications for blood pressure management: a systematic review on potential effects and initiatives. Stud Health Technol Inform. 2018;247:306-10.

20. Moher D, Liberati A, Tetzlaff J, Altman DG, Group P. Preferred reporting items for systematic reviews and meta-analyses: the PRISMA statement. PLoS Med. 2009;6(7):el000097.

21. Centers for Disease Control and Prevention. About chronic diseases. October 23, 2019. Available at: https://www.cdc.gov/chronicdisease/about/. Accessed February 24, 2020.

22. Higgins JPT, Thomas J, Chandler J, et al., eds. Cochrane Handbook for Systematic Reviews of Interventions. Version 6.0. Updated July 2019. Available at: www.training.cochrane.org/handbook. Accessed March 9, 2020.

23. Tao D, Xie L, Wang T, Wang T. A meta-analysis of the use of electronic reminders for patient adherence to medication in chronic disease care. J Telemed Telecare. 2015;21(1):3-13.

24. Hedges L, Olkin I. Statistical Method for Meta-Analysis. 1st ed. Orlando, FL: Academic Press, Inc; 1985

25. Cohen J. Statistical Power Analysis for the Behavioral Sciences. 2nd ed. New York: Lawrence Erlbaum Associates; 1998. Available at: http://www.utstat. toronto.edu/ brunner/oldclass/378f16/readings/CohenPower.pdf. Accessed February 24, 2020. 


\section{Effectiveness of Mobile Applications on Medication Adherence in Adults with Chronic Diseases: A Systematic Review and Meta-Analysis}

26. Egger M, Davey Smith G, Schneider M, Minder C. Bias in meta-analysis detected by a simple, graphical test. BMJ. 1997;315(7109):629-34.

27. Conn VS, Hafdahl AR, Cooper PS, Ruppar TM, Mehr DR, Russell CL. Interventions to improve medication adherence among older adults: meta-analysis of adherence outcomes among randomized controlled trials. Gerontologist. 2009;49(4):447-62.

28. Meader N, King K, Llewellyn A, et al. A checklist designed to aid consistency and reproducibility of GRADE assessments: development and pilot validation. Syst Rev. 2014;3:82

29. Saaty TL. The Analytic Hierarchy Process: Planning, Priority Setting, Resource Allocation. New York: McGraw-Hill; 1980.

30. Saaty TL. Decision making with the analytic hierarchy process. Int J Serv Sci. 2008;1:83-98.

31. Brath H, Morak J, Kastenbauer T, et al. Mobile health (mHealth) based medication adherence measurement: a pilot trial using electronic blisters in diabetes patients. Br J Clin Pharmacol. 2013;76(Suppl 1):47-55.

32. Marquez Contreras E, Marquez Rivero S, Rodriguez Garcia E, et al. Specific hypertension smartphone app to improve medication adherence in hypertension: a cluster-randomized trial. Curr Med Res Opin. 2019;35(1):167-73.

33. DeVito Dabbs A, Song MK, Myers BA, et al. A randomized controlled trial of a mobile health intervention to promote self-management after lung transplantation. Am J Transplant. 2016;16(7):2172-80.

34. Labovitz DL, Shafner L, Reyes Gil M, Virmani D, Hanina A. Using artificial intelligence to reduce the risk of nonadherence in patients on anticoagulation therapy. Stroke. 2017:48(5):1416-19.

35. Guo Y, Chen Y, Lane DA, Liu L, Wang Y, Lip GYH. Mobile health technology for atrial fibrillation management integrating decision support, education, and patient involvement: mAF App Trial. Am J Med. 2017;130(12):1388-96

36. Himelhoch S, Kreyenbuhl J, Palmer-Bacon J, Chu M, Brown C, Potts W. Pilot feasibility study of Heart2HAART: a smartphone application to assist with adherence among substance users living with HIV. AIDS Care. 2017:29(7):898-904

37. Kim JY, Wineinger NE, Steinhubl SR. The influence of wireless self-monitoring program on the relationship between patient activation and health behaviors, medication adherence, and blood pressure levels in hypertensive patients: a substudy of a randomized controlled trial. J Med Internet Res. 2016;18(6):el16.

38. Kleinman NJ, Shah A, Shah S, Phatak S, Viswanathan V. Improved medication adherence and frequency of blood glucose self-testing using an m-health platform versus usual care in a multisite randomized clinical trial among people with type 2 diabetes in India. Telemed J E Health. 2017;23(9):733-40

39. Mira JJ, Navarro I, Botella F, et al. A Spanish pillbox app for elderly patients taking multiple medications: randomized controlled trial. J Med Internet Res. 2014;16(4):e99.

40. Morawski K, Ghazinouri R, Krumme A, et al. Association of a smartphone application with medication adherence and blood pressure control: the MedISAFE-BP randomized clinical trial. JAMA Intern Med. 2018;178(6):802-09.
41. Santo K, Singleton A, Rogers K, et al. Medication reminder applications to improve adherence in coronary heart disease: a randomised clinical trial. Heart. 2019;105(4):323-29.

42. Sarfo F, Treiber F, Gebregziabher M, et al. PINGS (Phone-Based Intervention Under Nurse Guidance After Stroke): interim results of a pilot randomized controlled trial. Stroke. 2018;49(1):236-39.

43. Shah V, Dileep A, Dickens C, et al. Patient-centered tablet application for improving medication adherence after a drug-eluting stent. Front Public Health. 2016;4:272.

44. Svendsen MT, Andersen F, Andersen KH, et al. A smartphone application supporting patients with psoriasis improves adherence to topical treatment: a randomized controlled trial. Br J Dermatol. 2018;179(5):1062-71.

45. Kahana S, Drotar D, Frazier T. Meta-analysis of psychological interventions to promote adherence to treatment in pediatric chronic health conditions. J Pediatr Psychol. 2008;33(6):590-611.

46. Fu H, McMahon SK, Gross CR, Adam TJ, Wyman JF. Usability and clinical efficacy of diabetes mobile applications for adults with type 2 diabetes: a systematic review. Diabetes Res Clin Pract. 2017;131:70-81.

47. Ryan RM, Deci EL. Self-determination theory and the facilitation of intrinsic motivation, social development, and well-being. Am Psychol. 2000;55(1):68-78

48. Santo K, Richtering SS, Chalmers J, Thiagalingam A, Chow CK, Redfern J. Mobile phone apps to improve medication adherence: a systematic stepwise process to identify high-quality apps. JMIR Mhealth Uhealth. 2016;4(4):e132.

49. van den Berg N, Schumann M, Kraft K, Hoffmann W. Telemedicine and telecare for older patients: a systematic review. Maturitas. 2012;73(2):94-114.

50. Tseng KC, Hsu CL, Chuang YH. Designing an intelligent health monitoring system and exploring user acceptance for the elderly. J Med Syst. 2013;37(6):9967.

51. El-Gayar O, Timsina P, Nawar N, Eid W. Mobile applications for diabetes self-management: status and potential. J Diabetes Sci Technol. 2013;7(1):247-62.

52. Tatara N, Arsand E, Skrovseth SO, Hartvigsen G. Long-term engagement with a mobile self-management system for people with type 2 diabetes. JMIR Mhealth Uhealth. 2013;1(1):e1.

53. Pew Research Center Internet and Technology. Mobile fact sheet. June 12, 2019. Available at: www.pewinternet.org/fact-sheets/mobile-technologyfact-sheet. Accessed February 24, 2020.

54. Anglada-Martínez H, Rovira-Illamola M, Martin-Conde M, et al. mHealth intervention to improve medication management in chronically ill patients: analysis of the recruitment process. Postgrad Med. 2016;128(4):427-31.

55. Su D, Zhou J, Kelley MS, et al. Does telemedicine improve treatment outcomes for diabetes? A meta-analysis of results from 55 randomized controlled trials. Diabetes Res Clin Pract. 2016;116:136-48.

56. Weingart SN, Brown E, Bach PB, et al. NCCN Task Force Report: Oral chemotherapy. J Natl Compr Cancer Netw. 2008;6(Suppl 3):S1-14. 
Effectiveness of Mobile Applications on Medication Adherence in Adults with Chronic Diseases: A Systematic Review and Meta-Analysis

\section{APPENDIX A Risk of Bias Graph}

Random sequence generation (selection bias)

Allocation concealment (selection bias)

Binding of participants and personnel (performance bias)

Blinding of outcomes assessment (detection bias)

Incomplete outcome data (attrition bias)

Selective reporting (reporting bias)

Other bias

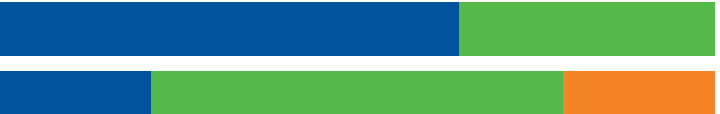

\section{)}

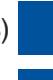

\section{)}
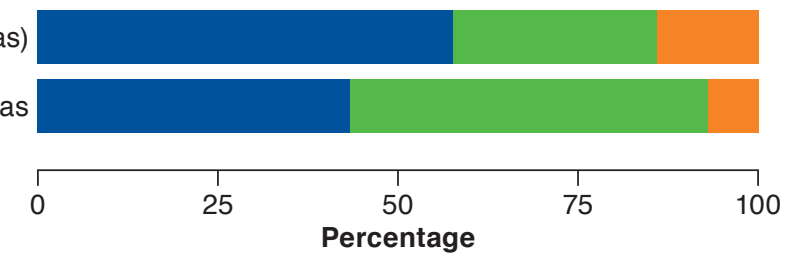

Low risk of bias Unclear risk of bias High risk of bias

Random sequence generation (selection bias)

Allocation concealment (selection bias)

Binding of participants and personnel (performance bias)

Blinding of outcomes assessment (detection bias)

Incomplete outcome data (attrition bias)

Selective reporting (reporting bias)

Other bias
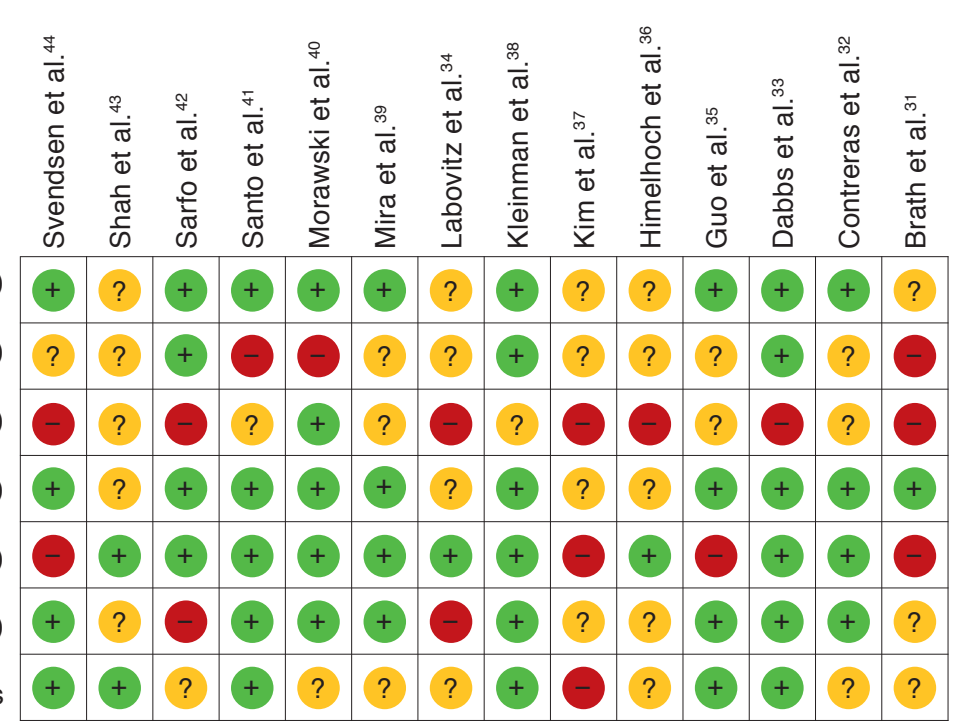

Low risk of bias? Unclear risk of bias

High risk of bias 
Effectiveness of Mobile Applications on Medication Adherence in Adults with Chronic Diseases: A Systematic Review and Meta-Analysis

\section{APPENDIX B GRADE of Evidence for Mobile Applications Compared with Usual Care on Medication Adherence} Authors: Yihang Peng, Han Wang, Liling Xie, Qin Fang, Lingzhi Shu, Wenjing Sun, Qin Liu

Date: March 3, 2019

Question: Is mobile application more effective than usual care in improving medication adherence for adults with chronic diseases? Settings: Outpatient clinic, hospital inpatient

Bibliography: Brath et al. (2013)31; Contreras et al. (2018)32; Dabbs et al. (2016)33; Guo et al. (2017)35; Himelhoch et al. (2017)36; Kim et al. (2016)37. Kleinman et al. (2017)38; Labovitz et al. (2017)34; Mira et al. (2014)39; Morawski et al. (2018) ${ }^{40}$; Santo et al. (2018) ${ }^{41}$; Sarfo et al. (2018) ${ }^{42}$; Shah et al. $(2016)^{43}$; Svendsen et al. $(2018)^{44}$

\begin{tabular}{|c|c|c|c|c|c|c|c|c|c|c|}
\hline \multicolumn{7}{|c|}{ Quality assessment } & \multicolumn{4}{|c|}{ Summary of findings } \\
\hline $\begin{array}{c}\text { No of } \\
\text { Studies }\end{array}$ & Design & Risk of Bias & Inconsistency & Indirectness & Imprecision & $\begin{array}{l}\text { Publication } \\
\text { Bias }\end{array}$ & $\begin{array}{l}\text { Intervention } \\
\text { (n) }\end{array}$ & Control (n) & $\begin{array}{l}\text { Standardized } \\
\text { Mean } \\
\text { Difference } \\
(95 \% \mathrm{CI})\end{array}$ & Quality \\
\hline \multicolumn{11}{|c|}{ Outcome: medication adherence } \\
\hline 14 & RCT & Serious ${ }^{\mathrm{a}}$ & Not serious ${ }^{\mathrm{b}}$ & Serious $^{\mathrm{c}}$ & Not serious ${ }^{\mathrm{d}}$ & Not serious ${ }^{\mathrm{e}}$ & 940 & 845 & $\begin{array}{c}0.40 \\
(0.27-0.52)\end{array}$ & Low \\
\hline
\end{tabular}

GRADE Working Group grades of evidence

High quality: Further research is very unlikely to change our confidence in the estimate of effect.

Moderate quality: Further research is likely to have an important effect on our confidence in the estimate of effect and may change the estimate.

Low quality: Further research is very likely to have an important effect on our confidence in the estimate of effect and is likely to change the estimate.

Very low quality: We are very uncertain about the estimate.

a Absence of blinding across studies. Downgrade 1 level.

${ }^{b}$ There was low heterogeneity $\left(I^{2}=29 \%, 95 \% C I=0 \%-62 \%\right)$ across the trials.

cOutcomes were measured on different methods in different studies. Participants have different chronic conditions. Apps in the intervention group have different features.

Downgrade 1 level.

dSample size is big enough to detect precise estimate of effect (more than 400) and wide 95\% CIs.

${ }^{e}$ The publication bias was undetected by Egger regression coefficient $(P=0.81)$. 